\title{
Pressure and resistance of the lips in subjects with and without occlusal change
}

\author{
Clarissa Evelyn Bandeira Paulino ${ }^{1}$ \\ https://orcid.org/0000-0002-9028-649X \\ José Rodrigues Laureano Filho \\ https://orcid.org/0000-0002-9645-2057 \\ Laís de Fátima Fonseca de Menezes ${ }^{1}$ \\ https://orcid.org/0000-0002-9370-4247 \\ Alípio Miguel da Rocha Neto² \\ https://orcid.org/0000-0003-3488-0950 \\ Luciana Moraes Studart-Pereira ${ }^{1}$ \\ https://orcid.org/0000-0003-0030-1463
}

\section{Universidade Federal de Pernambuco, Recife, Pernambuco, Brasil. \\ 2 Universidade de Pernambuco, Camaragibe, Pernambuco, Brasil. \\ Conflict of interests: Nonexistent}

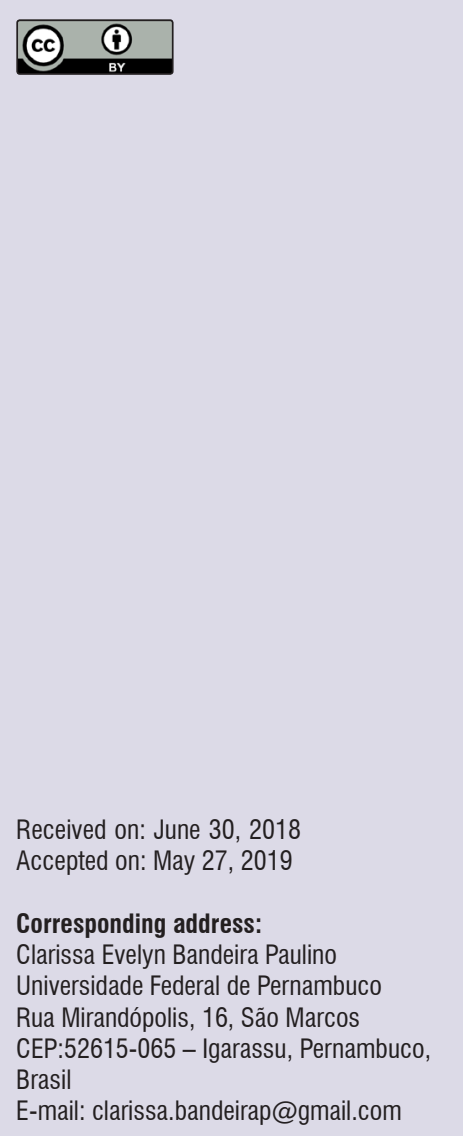

\section{ABSTRACT}

Objective: to evaluate the resistance and pressure of the lips in Class I, II and III Angle's malocclusion subjects, in comparisonto reference values and relate them with gender and age.

Methods: a quantitative, descriptive and cross-sectional study. Participants included 40 subjects, 20 women and 20 men, average age 26.3 years, separated by occlusal classification. The volunteers answered on the self-reported performance of the stomatognathic functions and were submitted to the evaluation of the mobility and posture of the lips. Pressure and resistance were measured with the lowa Oral Performance Instrument (IOPI) and the results compared to the reference values described in the instrument's manual. The data were analyzed descriptively and, for inferential analysis, Pearson's Chi-Square test was used. The significance level was considered $5 \%$.

Results: a decrease in pressure and resistance values wasobserved in all patients, including Angle's class I group. There was an inverse relationship between the age of the subjects and the values of pressure of lips with statistical significance $(p=0.02)$. In general, women had lower pressure values than men.

Conclusion: all study subjects had lower pressure of the lips than the reference values described in the literature.

Keywords: Lip; Dental Occlusion; Dentofacial deformities 


\section{INTRODUCTION}

The lips are important anatomical units for harmony and facial aesthetics. They are dentistry and speech pathology targets of interest mainly from the functional point of view. This is a structure that can be clinically evaluated by observation and palpation when one aims to identify its usual position ${ }^{1-3}$.

Perioral muscles and positioning of the lips, especially the activity of the orbicularis oculi muscle of the mouth constitute factors determining the characteristics of the teeth and tooth position. The usual sealing and resting of the lips help in defining and maintaining occlusion 4 .

People with incompetent lips cannot seal lips effortlessly in the usual position. Thus, it becomes a condition that can promote dental imbalance by reducing the pressure of the lips acting on them, generating changes that can affect various functions such as breathing, growth and harmonious development of face ${ }^{5}$.

Subjects with maxillomandibular disproportions have myofunctional and facial profile characteristics according to the type of disproportion of that feature. Muscle adaptations that occur in various types of dentofacial deformities (DFD) enable the realization of stomatognathic functions that are performed according to the pattern of the maxillofacial skeleton bone structure ${ }^{6}$.

Disharmonies of the craniofacial complex result in pathophysiological adjustments to task implementation. The intimate relationship between the hard and soft tissues as well as the need to perform the stomatognathic functions for survival, leading to the occurrence of functional adaptations in order to allow the execution of these, independently of existing alterations. In this process, the function and morphology are closely linked, as the harmonic structure's condition directly affects the muscular behavior balance ${ }^{7,8}$.

When there is an adequate morphological pattern, lips make up one of the structures that act as the local homeostasis maintainers. In this sense, the shape and integrity of the dental arches are dependent on factors such as the contact relationship between adjacent teeth and muscular activity9.

Changes in posture, especially of the lips, tongue, and cheeks entail a loss in the antagonistic mechanism of orofacial muscles. This fact causes the teeth to seek other positions of equilibrium, generating craniofacial changes ${ }^{10}$. Alterationoccurring in soft tissues is bone-related characteristics of the individual and speech-language, the authors suggest that may be an ally in the identification of these specificities ${ }^{11}$.

Although there is a method that is considered the gold standard for objective measurement of the lips, the study of muscular behavior is necessary, since it can help in understanding the force exerted by the perioral muscles on dentition, besides serving as a parameter in the evaluation of speech saliva of control, facial expression, feeding and labial sealing ${ }^{12,13}$.

There are studies that relate the pressure of the lips and tongue on the type of malocclusion. However, the literature lacks studies to evaluate the resistance of these changes related to dental bone structures ${ }^{14,15}$.

In this investigation, it was decided to use the lowa Oral Performance Instrument (IOPI), characterized by an air pressure device that uses a plastic bulb to measure the pressure, so that the bulb is positioned in the structure being evaluated, avoiding the tooth contact. In addition, the IOPI is a portable instrument, easy to handle, use and hygiene, developed with the purpose of measuring pressure and resistance of tongue, lips, and cheeks ${ }^{16}$. It is an equipment that also presents normality standard values, tested in patients without changes, which served as a parameter for making comparisons with the study population.

Given the importance of the occlusion of the lips for holding the stomatognathic system, it is understood that the knowledge of the behavior of pressure measurement and resistance lips proposed in this study allows to identify the specificity of the difficulty of people with malocclusion and collaborates with therapeutic approaches propositions.

Therefore, this study aimed to evaluate the pressure and resistance of the lips in subjects with Angle's Class I, II and III malocclusion, compared to reference values and relate them with sex and age. The research was based on the assumption that people with malocclusion present lower values of pressure and resistance of the lipsas compared to those without malocclusion, according to the reference values proposed by the manufacturer of the instrument used.

\section{METHODS}

This was a quantitative, descriptive and cross-sectional study, approved by the Ethics Committee on Human Research of the University of Pernambuco under number 1780737 held in a university hospital with candidates for orthognathic surgery, attendant to a referral service in Oral and Maxillofacial Surgery, and students without malocclusion (Class I). Participants 
were separated based on the occlusal relationship between the dental arches by the dentistry team. The ratio was found according to the Angle's classification in Class I, II and III of the first molars and canines.

The sample comprised of 40 volunteers who had the presence of all permanent teeth except for the third molars, including 20 women and 20 men, aged between 17-41 years, average age of 26.3 years, who were divided, according to Angle's classification, namely: Class I, containing ten subjects; Class II, five subjects and Class III, twenty-five subjects.

The study included people who did not present change on the mobility of thelips and/or posture that prevented holding the instrument bulb. As exclusion criteria: neurological disorders, cognitive disorders, syndromes, facial trauma history or head and neck cancer, have been subjected to orthognathic surgery or speech therapy prior to evaluation was used.

Initially, the volunteers responded to questions related to personal identification, record the presence or absence of a complaint on chewing, swallowing and speaking. Further, they underwent myofunctional assessment, focusing on the position and mobility of the lips, following the methodological approach of another study ${ }^{17}$, which used the same device for tongue pressure measurement. To evaluate the lips of mobility tests, it was asked the participant to perform the following movements: bulging, retract and lateralize lips to the right and left. The posture was scored as a normal position of the lips, closed, closed with tension, parted, closed in dental contact and open.

The movements were observed simultaneously by two evaluators and the result was only filled on the collection form after agreement between them. When in doubt, participants were asked to repeat the above movement. For this evaluation, the participant was sitting with his head in normal position. When there was a doubt as to the realization of some command, one of the researchers showed the model.

Each item from the lips of mobility assessment received a score that could range from zero to three, where zero is the "normal" movement, one "approximate", two refers to "attempts to perform" three to "did not perform". For evaluation of this performance, an adaptation of the item of the mobility of the lips of the Myofunctional Orofacial Examination- MBGR ${ }^{18}$ protocol was used.

Participants who scored higher than or equal to five in the sum of the movements, i.e., not performed any of the movements and tried to do another, or tried to perform three of them, or presented lips posture unfeasible on holding the bulb, were considered with significant changes, and therefore were not part of the research. That cut point was considered, because the non-operation of more than one motion, the sum of "did not perform" plus "attempts to perform" or all "attempts to perform" would interfere in the results of measurement, bearing in mind that the assessment needed the relative contribution of occlusion of the lips. Three subjects were excluded due to a score greater than five.

Later, the volunteers were instructed on how the measurements of pressure and resistance of the lips would be held. In this second stage, to evaluate these parameters, the Oral Instrument Performance (IOPI), 2.0 model was used.

IOPI is an apparatus that aims to demonstrate the pressure and resistance of lips through the numbers in the unit kiloPascal $(\mathrm{kPa})$.This instrument consists of a yield meter which allows the visualization of the force exerted on the air sensor, sensors (bulbs), the connection pipe connecting the sensor to the meter, and a syringe for a pressure check. It is noteworthy that, for this study, the device was calibrated as directed by manual ${ }^{19,20}$ every use in ten subjects.

To measure the pressure of the lips the evaluator disposed the bulb between two spatulas, positioning in the voluntary lips so that there was no involvement of the teeth during clenching. For this, the bulb was positioned in front of the incisors. Following were asked to volunteer to exert the maximum possible sealing for a period of two seconds. 


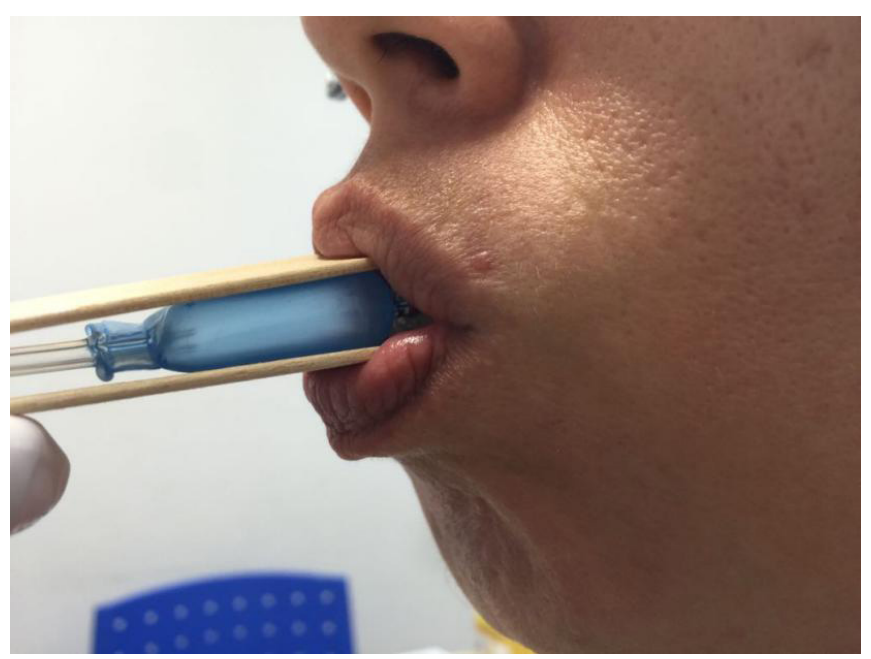

Figure 1. Measurement of the pressure of the lips

This measurement was performed three times with 30-second intervals. It was considered the largest peak measured pressure value of the three results obtained according to the IOPI manual.

Finally, after five minutes of rest, for resistance measurement, the same subjects received the bulb placement orientations between the lips. However, for this measure, they should keep up the pressure for as long as they could. It used $50 \%$ of its maximum pressure and the participants could monitor their performance through IOPI light display. The time was recorded in a chronograph. The answers regarding the pressures and resistance were recorded in a specific form. If the participant could not perform with the value of $50 \%$ of the highest measured pressure was subtracted gradually one $\mathrm{kPa}$ at a time, the amount corresponding to half the highest peak pressure, to establish a value for it to be possible to obtain the measurement in seconds.
The IOPI manual has reference values only for the pressure lips. Measurements to the resistance in seconds (s) are not specified or described in the literature. Thus, the parameter was set to be the resistance values corresponding to $50 \%$ of the pressure of the lips. For this calculation, we used the logic values of the tongue used for the resistance. Thus, it was considered appropriate values greater than or equal to 15 seconds as it refers to half the average $(31.5 \mathrm{kPa})$ of pressure reference values for the lips $(28 \mathrm{kPa}$ for women and $35 \mathrm{kPa}$ for men).

The data were organized for the procedure of descriptive analysis, obtaining statistical measures: average, standard deviation (SD) and median. For inferential analysis of the variables, we used the non-parametric Chi-squared and Pearson Chi-square test. A $5 \%$ significance level was adopted. The software used was the Statistical Package for Social Sciences (SPSS) version 22.0.

\section{RESULTS}

The participants were distributed following Angle's classification: Class I (25\%, $n=10)$, Class II (12.5\%, $n$ $=5)$ and Class III (62.5\%, $n=25)$.

On the conformity of pressure and resistance of the lips in different occlusal ratings, when compared to the reference values set out in $|\mathrm{OP}|^{19}$ the manual is possible to observe a decrease in pressure and resistance in all subjects, including the group with normal occlusion since there was no difference for the statistical test. Pressure values in the Class III group showed statistical significance for both females and males (Table 1). 
Table 1. Pressure and resistance of the lips, according to the occlusion

\begin{tabular}{|c|c|c|c|c|c|}
\hline & & $\begin{array}{l}\text { According to } \\
\text { reference values }\end{array}$ & $\mathbf{N}$ & $\mathbf{N}$ & p-value ${ }^{1}$ \\
\hline \multirow{17}{*}{ Pressure } & \multirow{2}{*}{ Class I } & Yes & 3 & \multirow{2}{*}{10} & \\
\hline & & No & 7 & & \\
\hline & \multirow{2}{*}{ Class I Females } & Yes & 1 & \multirow{2}{*}{4} & \multirow{2}{*}{0.31} \\
\hline & & No & 3 & & \\
\hline & \multirow{2}{*}{ Class I Males } & Yes & 2 & \multirow{2}{*}{6} & \multirow{2}{*}{0.41} \\
\hline & & No & 4 & & \\
\hline & \multirow{2}{*}{ Class II } & Yes & 1 & \multirow{2}{*}{5} & \\
\hline & & No & 4 & & \\
\hline & \multirow{2}{*}{ Class II Females } & Yes & 1 & \multirow{2}{*}{5} & \multirow{2}{*}{0.18} \\
\hline & & No & 4 & & \\
\hline & Class II Males & - & - & - & - \\
\hline & \multirow{2}{*}{ Class III } & Yes & 3 & \multirow{2}{*}{25} & \\
\hline & & No & 22 & & \\
\hline & \multirow{2}{*}{ Class III Females } & Yes & 2 & \multirow{2}{*}{11} & \multirow{2}{*}{$0.03^{*}$} \\
\hline & & No & 9 & & \\
\hline & \multirow{2}{*}{ Class III Males } & Yes & 1 & \multirow{2}{*}{14} & \multirow{2}{*}{$0.001^{*}$} \\
\hline & & No & 13 & & \\
\hline & \multirow{2}{*}{ Class I } & Yes & 3 & \multirow{2}{*}{10} & \\
\hline & & No & 7 & & \\
\hline & \multirow{2}{*}{ Class I Females } & Yes & 1 & \multirow{2}{*}{4} & \multirow{2}{*}{0.31} \\
\hline & & No & 3 & & \\
\hline & \multirow{2}{*}{ Class I Males } & Yes & 2 & \multirow[t]{2}{*}{6} & 0.41 \\
\hline & & No & 4 & & \\
\hline & Class ॥ & Yes & 1 & 5 & \\
\hline & Class II & No & 4 & 5 & \\
\hline Resistance & Class II Females & Yes & 1 & 5 & 0.18 \\
\hline 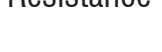 & Class in remales & No & 4 & & 0.18 \\
\hline & Class II Males & - & - & - & - \\
\hline & Clacc II & Yes & 11 & 25 & \\
\hline & Class III & No & 14 & 20 & \\
\hline & Class III Females & Yes & 3 & 11 & 0.13 \\
\hline & & No & 8 & & \\
\hline & Class III Males & Yes & 8 & 14 & 0.59 \\
\hline & & No & 6 & 14 & \\
\hline
\end{tabular}

* Chi-square test - Significant * $-p<0.05$

Caption: $\mathrm{N}=$ Total number $/ \mathrm{n}=$ number of subgroups

The median values representing the pressure of the lips as the occlusion, it is possible to observe the subject in median values below malocclusion group values unchanged (Figure 2).

When subgroups described by considering the sex of subjects per study group, Class I subjects have the average pressure of $29.50 \mathrm{kPa}$ men and median of $30.00 \mathrm{kPa}$, and the minimum and maximum values of 16 and 48 Kpa respectively, with a standard deviation of $11.79 \mathrm{kPa}$ for men. The women showed lower values with an average of $20.75 \mathrm{kPa}$ and a median of 22.00 $\mathrm{kPa}$, with a minimum of $10 \mathrm{kPa}$, a maximum of $29 \mathrm{kPa}$ and a standard deviation of $8.53 \mathrm{kPa}$.

In the Class II group there was no sample in men and women had an average and median of $16.80 \mathrm{kPa}$ to $15.00 \mathrm{kPa}$ of pressure ranging between 2 and 28 with $\mathrm{SD}=10.28 \mathrm{KPa}$. In the Class III group, the mean values of the pressure of the lips also were lower in women (15.55 kPa) compared to men $(16.29 \mathrm{kPa})$, but very 
close. The median was 13.00 and $15.50 \mathrm{Kpa}$ respectively in females and males.

Regarding the minimum and maximum pressure values women showed 4 and $36 \mathrm{kPa}$ with a SD equal to 9.21. The two men had a variation of 2 and $51 \mathrm{kPa}$ SD of $11.58 \mathrm{kPa}$.
With regard to age, there is an inverse relationship between lips pressure values in studied subjects with statistical significance $(p=0.02)$ (Figure 3$)$.

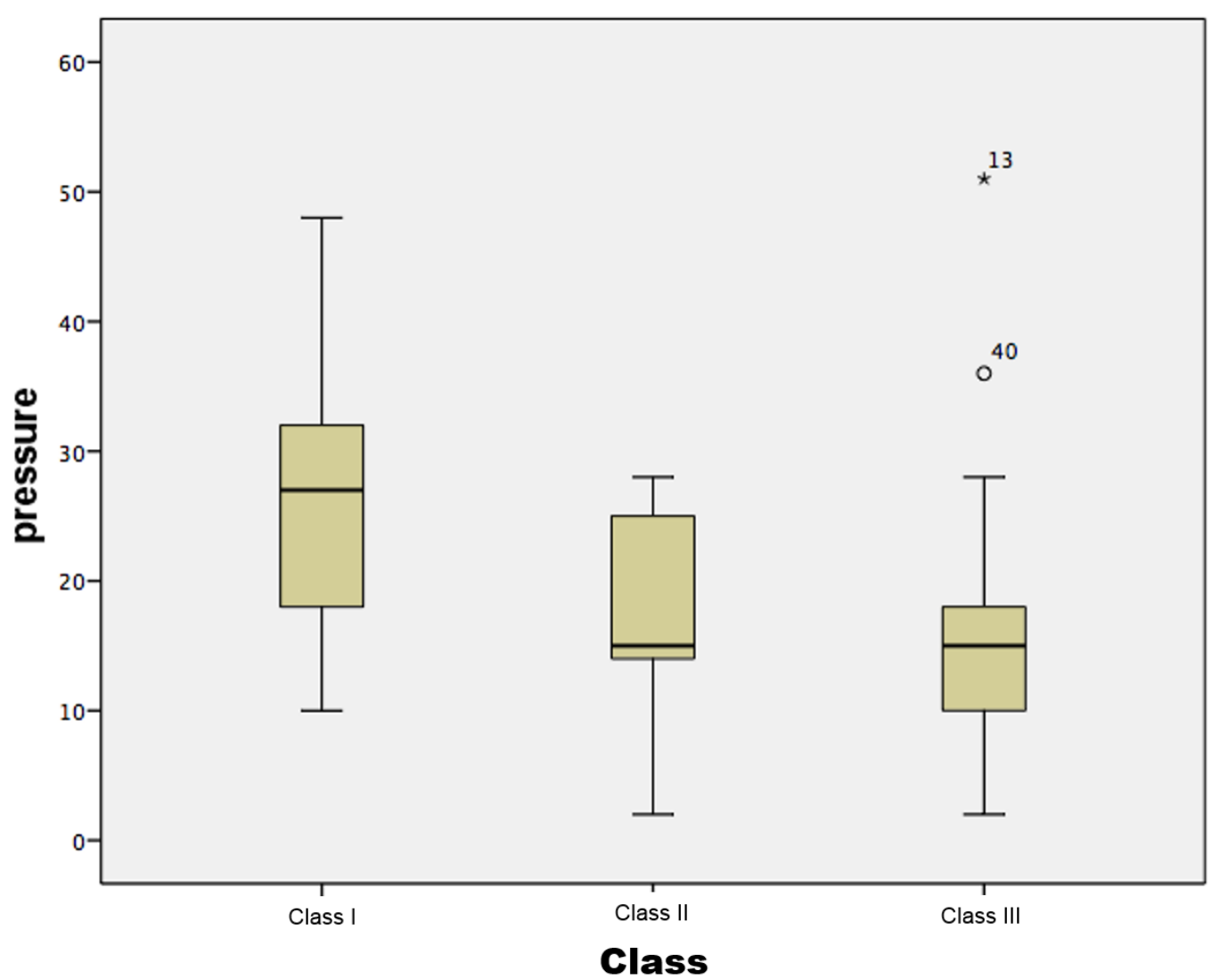

Figure 2. Median values of the pressure of the lips, according to the occlusion

Considering the values of resistance of the lips by subgroup, Class I subjects had an average of 14.75 seconds with a standard deviation of plus or minus 9.94 seconds and a median of 12.00 seconds with 6 seconds as a minimum value and 29 seconds as a maximum, for females. Men had average values and SD of 16.17 seconds and plus or minus 13.67 seconds respectively, a median of 12.50 seconds with a minimum value of 2 seconds and a maximum equal to 41 seconds.
The Class II group had an average of 14.20 seconds SD of about 15.33 seconds, a median of 10.00 ranging from 2 seconds to 41 seconds. In the Class III group, females had an average of 14.82 seconds and the males were 41.57 seconds with SD of about 15.81 and 64.32 seconds respectively. Women had a median of 11.00 seconds, ranging from 2 to 57 seconds and the men had the measure equal to 23.50 seconds, with a minimum value of 1 and a maximum of 243 seconds. For the resistance of the lips, no group showed statistical significance (Table 2). 


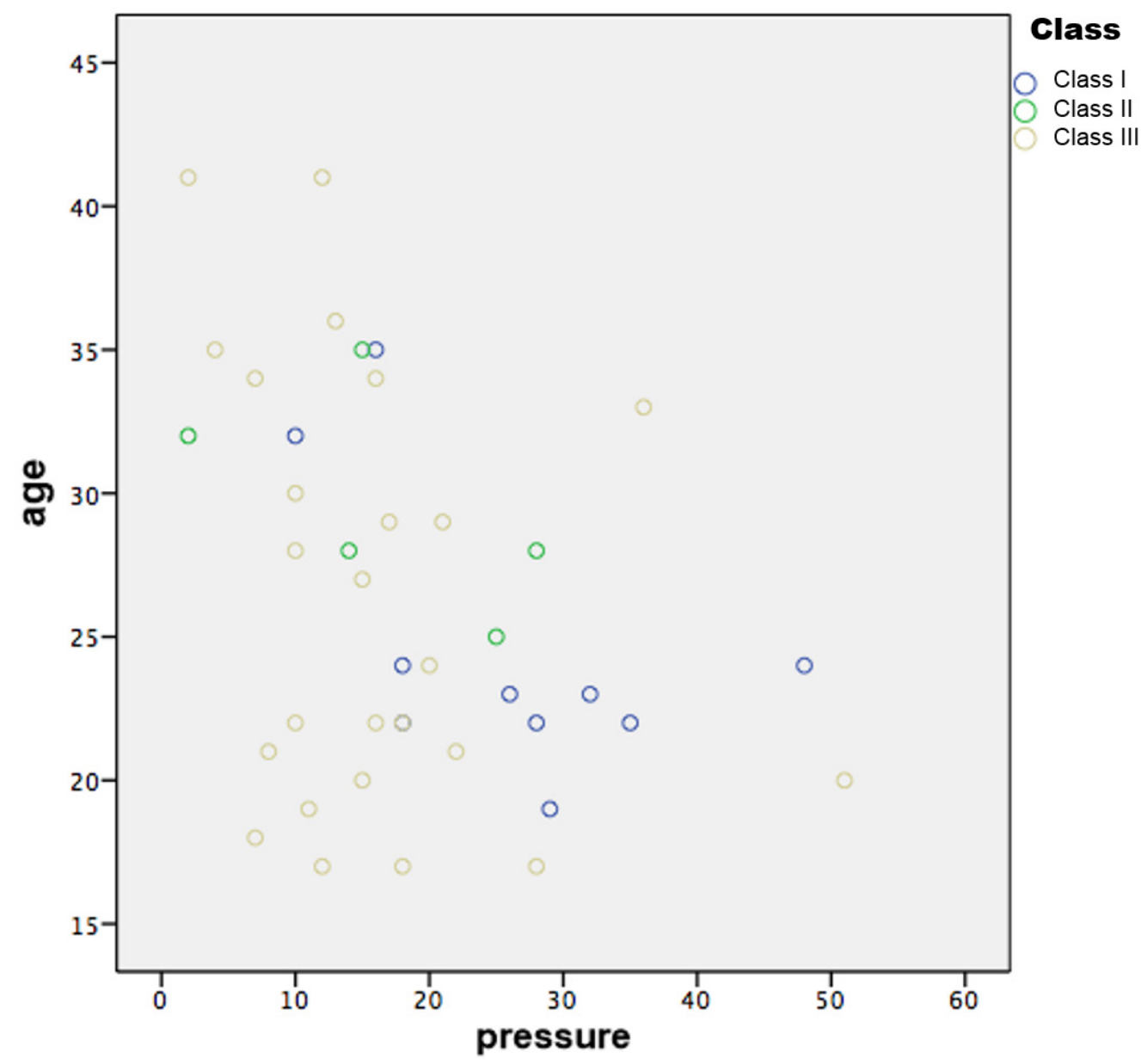

Figure 3. Relationship between the age and the pressure of the lips

Table 2. Resistance of the lips, according to the subgroup

\begin{tabular}{|c|c|c|c|c|}
\hline & & Average \pm SD (s) & Median (s) & Reference Value (s) \\
\hline \multirow{12}{*}{ Resistance } & Class I & 14.75 & 12.00 & \multirow{2}{*}{15} \\
\hline & Females & $( \pm 9.94)$ & $(6-29)$ & \\
\hline & Class I & 16.17 & 12.50 & \multirow{2}{*}{15} \\
\hline & Males & $( \pm 13.67)$ & $(2-41)$ & \\
\hline & Class II & 14.20 & 10.00 & \multirow{2}{*}{15} \\
\hline & Females & $( \pm 15.33)$ & $(2-41)$ & \\
\hline & Class II & 1 & & \multirow{2}{*}{ - } \\
\hline & Males & & & \\
\hline & Class III & 14.82 & 11.00 & \multirow{2}{*}{15} \\
\hline & Females & $( \pm 15.81)$ & $(2-57)$ & \\
\hline & Class III & 41.57 & 23.50 & \multirow{2}{*}{15} \\
\hline & Males & $( \pm 64.32)$ & $(1-243)$ & \\
\hline
\end{tabular}


Given the average pressure per group, it realizes a decrease of values in groups with occlusal change compared to the group without change (Figure 4). Regarding sex, women had a lower average pressure than men (Figure 5). Since the resistance values, the Class III group had an average higher than the other (Figure 6). The differences identified were observed in the statistical test used.
In Figure 4, it is observed that the average pressure changes of the occlusal groups (Class II and III) are lower than the group without malocclusion. With regard to sex, women had an average pressure lower than men (Figure 5). Regarding the resistance values, the Class III group had a higher average than the other (Figure 6).

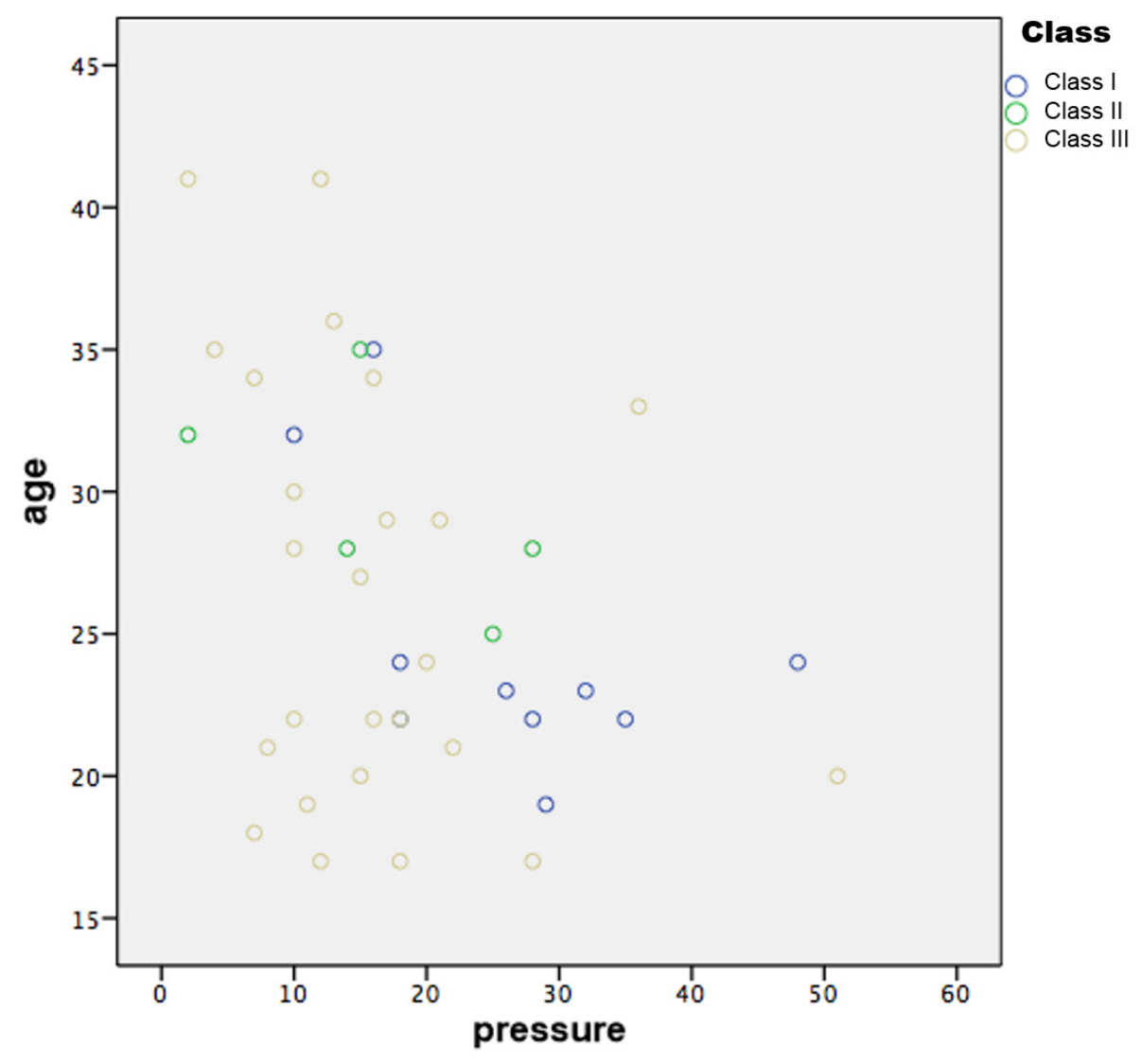

Figure 4. Relationship between the pressure and the occlusion of the lips 


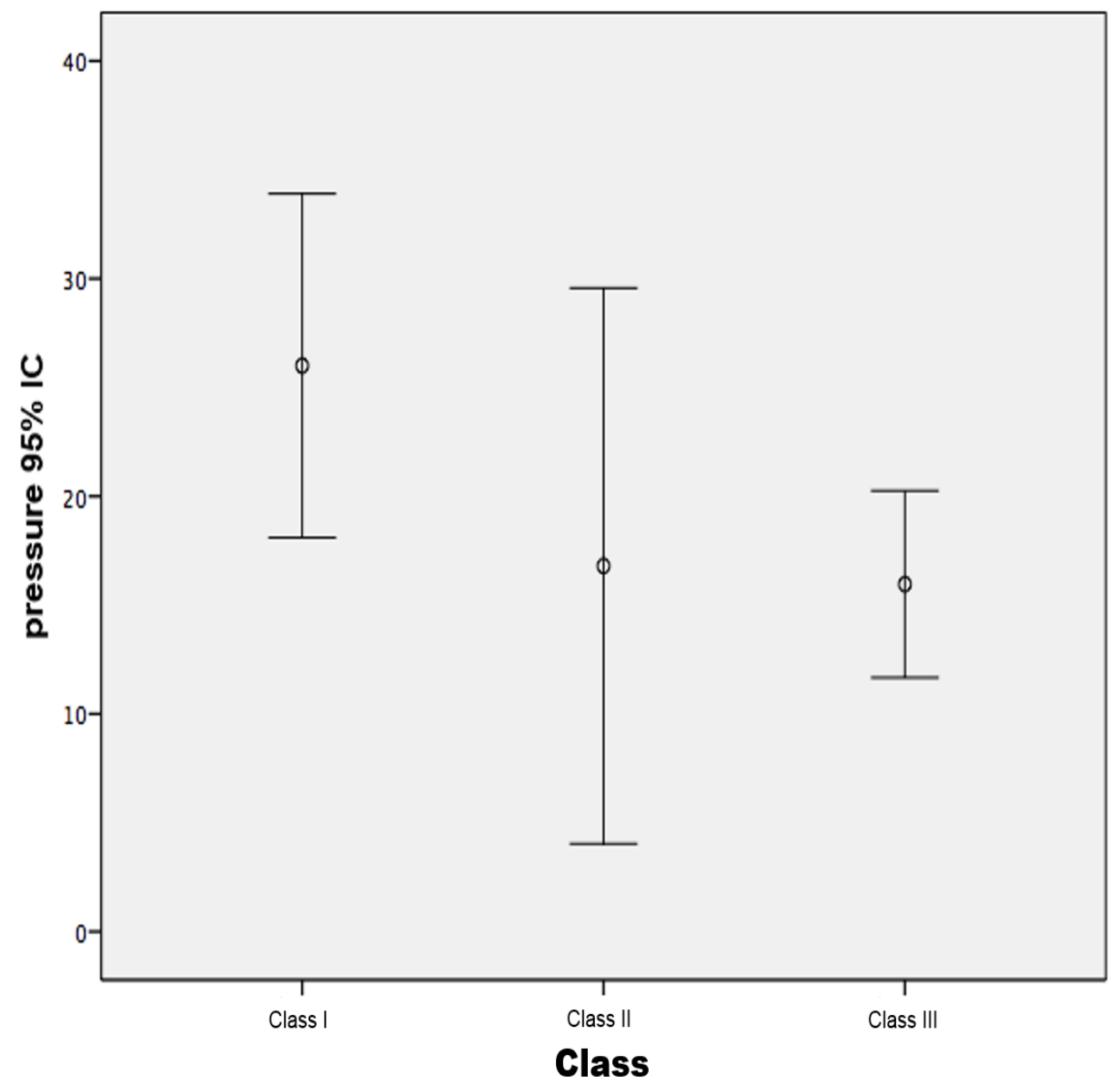

Figure 5. Relationship between the pressure of the lips and the sex

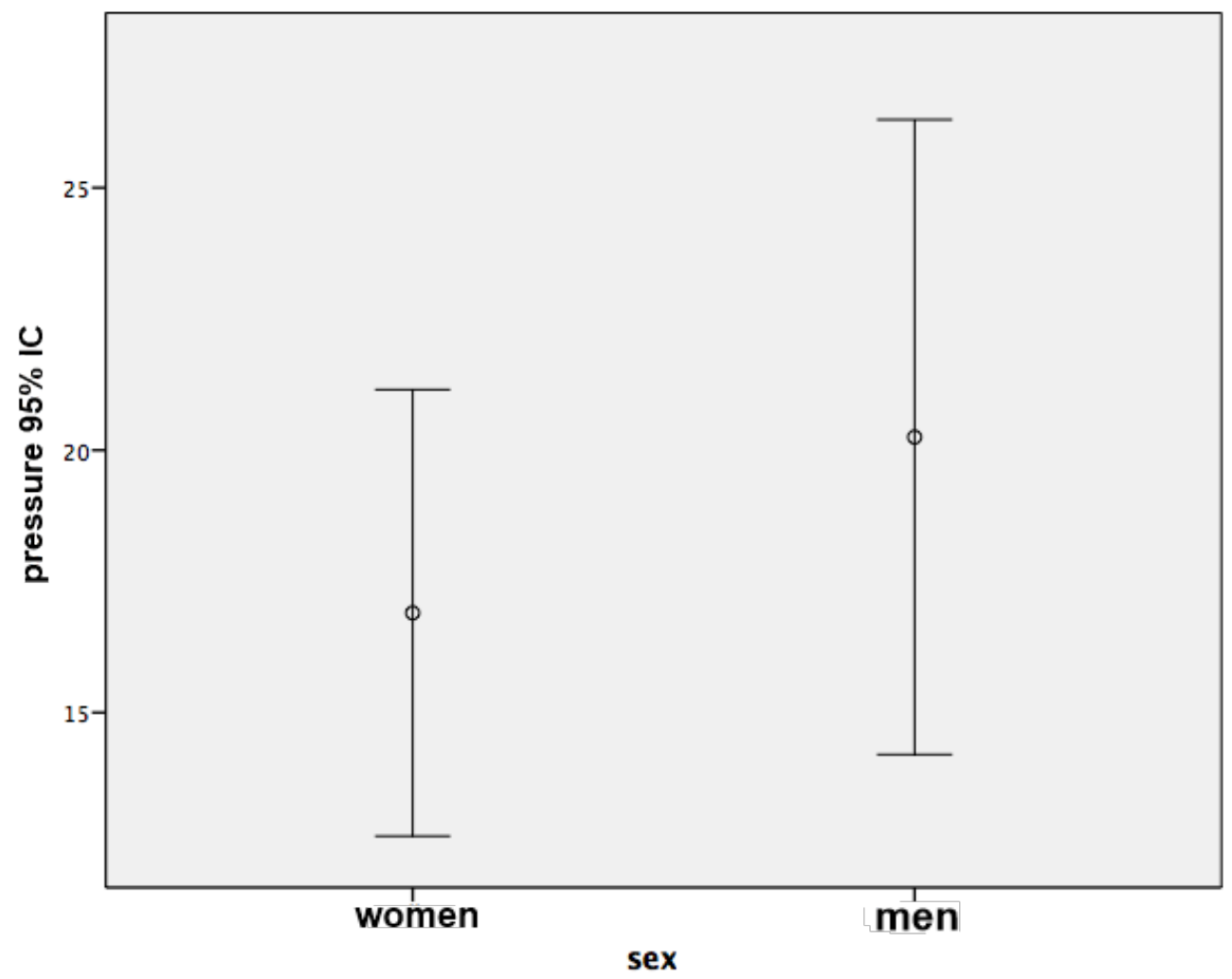

Figure 6. Relationship between the resistance and the occlusion of the lips 


\section{DISCUSSION}

In general, the subjects of this study showed low values of pressure of the lips, corroborating with other studies that evaluated the said structure under other conditions ${ }^{21-25}$. Improper pressure peak of Class I subjects may be explained by the fact of not having been considered, differences in the facial profile of the subjects (dolichofacial, mesofacial and brachyfacial), whereas, in the vertical plane, literature also reports muscular pattern modification in structure function ${ }^{6}$. In addition, the population of subjects without change, studied for the reference values of IOPI, is of American nationality ${ }^{16}$, which could have differed from subjects of this research due to ethnic differences. Some studies $^{26,27}$ already noted the influence of ethnicity on the dimensions and proportions of teeth.

It is emphasized that despite the pressure values of Class I subjects also present inadequate, according to the reference values of the IOPI manual, it is observed even without a statistical difference, that the average pressure of the lips of the groups with abnormal occlusal are lower than the Class I group (Table 1). This justifies for patients with maxillomandibular disproportions, for example in the case of individuals with maxillary protrusion, presents a change in pressure of the lips with less force in closing this structure ${ }^{13,28,29}$.

The absence of closure of the lips in Class II patients can provide greater involvement of the muscles of the lips and cheeks over the area of the maxillary dentition when compared to subjects with normal occlusion. This is due to compensations and adaptations where the orbicular muscle exerts force on the upper posterior teeth, which will cause retroinclination, besides the negative pressure within the oral cavity ${ }^{30}$. In relation to the Class III group, is also described in the literature decreased the lips closure pressure as compared to Class I individuals ${ }^{31}$.

The results of this study also show in a descriptive observation that women had lower peak pressure relative to men. The Class III group values are very close to an average pressure of $15.55 \mathrm{kPa}$ in women and $16.29 \mathrm{kPa}$ in men. The medians were 13.00 and $15.50 \mathrm{kPa}$, respectively, in the females and males. Regarding the minimum and maximum values, women had values of 4 and $36 \mathrm{kPa}$, with SD equal $9.21 \mathrm{kPa}$. The men had a variation of 2 to $51 \mathrm{kPa}$ and $\mathrm{SD}=11.58$.

A study ${ }^{13}$ with subjects without dentofacial changes also pointed out that males have pressure of the lips values similar to the females. However, when analyzing Class III subjects of this study, there was a greater pressure of the lips during the sealing in men than in women, with significant results, which are findings that corroborate with other studies ${ }^{31,32}$ that related to the pressure of the lips and sex in patients with dentofacial deformity.

Regarding the resistance patterns, it is observed that men, although not statistically significant, have the resistance of the lips values, greater than that of women. Both men of Class I and Class III group were within the normal range for this study. On the other hand, the women, although values were below the reference, presented very close values in all the groups. This can be justified by the fact that in order to measure the resistance, we used half the individual peak pressure, and sometimes adapting to the gradual reduction of the pressure value as described in the method, leading the individual to provide varying resistance as the pressure applied to be smaller or larger. Thus, it was not possible to establish the relationship between the resistance and other variables, since it depended on the result of pressure. This question is justified, also, the SD disparity in relation to the averages presented by subgroup (Table 2 ).

On the above question, the authors report that the maximum strength of a particular muscle is the ability of this muscle group create tension to a specific movement while the muscular strength depends on the training and quality of muscular contraction ${ }^{33}$.

With regard to age, the findings of this research showed lower pressure of the lips in older subjects. In the same vein, it was observed a decrease of pressure values with age in a study ${ }^{34}$ that evaluated the tongue pressure with IOPI in subjects with malocclusion. In contrast, a sample of children in Class II has used a nozzle connected to a dynamometer for assessing the resting lips and the function, it has been found that the performance of lips tended to increase with age ${ }^{35}$.

With aging, decreased muscle tissue and its function, and decreasing atrophy of muscle fibers and reducing the number of motor units as a result of sarcopenia can justify the anatomical and physiological changes $^{36-38}$. In this sense, the natural consequences of biological aging, alone might justify a reduction in the pressure of the lips with age.

This work presents limitations due to the disparity between subgroups of the sample. This heterogeneity is justified, because the demand for surgical correction, to be more frequent in patients with mandibular prognathism ${ }^{39}$. However, the evaluation of pressure 
and resistance of the lips shows a relation between variables of the study.

Therefore, it is suggested conducting further research to evaluate pressure and resistance of the lips with IOPI in a more homogeneous sample of patients with malocclusion and populational studies that measure the resistance in subjects without occlusion alterations, so as to obtain parameters of normality.

\section{CONCLUSION}

There was a decrease in pressure in all the subjects of the sample being lower in subjects with malocclusion, when compared to the reference values described in the literature. The Class III subjects showed a decrease in pressure and an increase in resistance, but an association was not established.

The values of pressure of the lips were higher in men than in women and it has been also noted that the pressure of the lips tends to decrease within age.

\section{THANKS}

To the Laboratory of Orofacial Motricity / Aerodynamics Assessment of Breathing and Speech of the Department of Speech Pathology, of the Federal University of Pernambuco.

\section{REFERENCES}

1. Philipp-Dormston WG, Hilton $S$, Nathan M. A prospective, open-label, multicenter, observational, postmarket study of the use of a $15 \mathrm{mg} / \mathrm{mL}$ hyaluronic acid dermal filler in the lips. $\mathrm{J}$ Cosmet Dermatol. 2014;13(2):125-34.

2. Prandini EL, Totta T, Bueno MRS, Rosa RR, Giglio LD, Trawitzki LVV et al. Analysis of tongue pressure in brazilian young adults. CoDAS. 2015;27(5):478-82.

3. Berwi LC, Ritzel RA, Silva AMT, Mezommo CL, Côrrea ECR, Serpa EO. Usual tongue and lips position in anteroposterior and vertical growth patterns. Rev. CEFAC. 2015;17(Supl1):107-14.

4. Rezende MS, Carvalho LC, Prado RAM, Rocha CBJ, Silva VR, Lunes DH. Isostretching method effects on lung function and posture of mouth breathers. ConScientiae Saúde. 2016;15(1):89-95.

5. Imbaud TCS, Mallozi MC. Frequência de rinite e alterações orofaciais em pacientes com má oclusão dentária. Rev Paul Pediatr. 2016;34(2):184-8.

6. Migliorucci RR, Sovinski SRP, Passos DCBDO, Bucci AC, Salgado $\mathrm{MH}$, Nary Filho $\mathrm{H}$ et al.
Orofacial functions and quality of life in oral health in subjects with dentofacial deformity. CoDAS. 2015;27(3):255-9.

7. Prado DGDA, Sovinski SRP, Nary Filho $H$, Brasolotto $A G$, Felix GB. Oral motor control and orofacial functions in individuals with dentofacial deformity. Audiol., Commun. Res. 2015;20(1):76-83.

8. Trench JA, Araújo RPC. Dentofacial deformities: orofacial myofunctional characteristics. Rev. CEFAC. 2015;17(4):1202-14.

9. Domann J, Cruz CM, Crepaldi MV, Crepaldi MLS, Oliveira BLS. Mordida aberta anterior, etiologia, diagnóstico e tratamento precoce. Rev. FAIPE. 2016;6(2):1-14.

10. Pacheco MCT, Fiorott BS, Finck NS, Araújo MTM. Craniofacial changes and symptoms of sleepdisordered breathing in healthy children. Dental Press J Orthod. 2015;20(3):80-7.

11. Silva MFN, Toni LDM. Fonoaudiologia e cirurgia ortognática: revisão de literatura. Rev. bras. cir. plást. 2018;33(3):404-13.

12. Šidlauskienè $M$, Smailienè $D$, Lopatienè $K$, Čekanauskas E, Pribuišienè $R$, Šidlauskas $M$. Relationships between malocclusion, body posture. Rev. Medical Science Monitor: International medical journal of experimental and clinical research. 2015; 21:1765-73.

13. Sjögreen L, Lohmander A, Kiliaridis S. Exploring quantitative methods for evaluation of lip function. $J$ Oral Rehab. 2011;38(6):410-22.

14. Lambrechts H, De Baets E, Fieuws S, Willems G. Lip and tongue pressure in orthodontic patients. Eur J Orthod. 2010;32(4):466-71.

15. Clark HM, Solomon NP. Age and sex differences in orofacial strength. Dysphagia. 2012;27(1):2-9.

16. Adams V, Mathisen B, Baines S, Lazarus C, Callister R. A systematic review and meta-analysis of measurements of tongue and hand strength and endurance using the lowa Oral Performance Instrument (IOPI). Dysphagia. 2013;28(3):350-69.

17. Magalhães Junior VH, Tavares JC, Magalhães $A A B$, Galvão HC, Ferreira MAF. Characterization of tongue pressure in the elderly. Audiol., Commun. Res. 2014;19(4):375-9.

18. Genaro KF, Berretin-Felix G, Rehder MIBC, Marchesan IQ. Avaliação miofuncional orofacial: protocolo MBGR. Rev. CEFAC. 2009;11(2):237-55.

19. IOPI Northwest. lowa oral performance instrument: user's manual. Carnation: IOPI Northwest; 2011. 
20. Reis VS, Araújo TG, Furlan RMMM, Motta AR. Correlation between tongue pressure and electrical activity of the suprahyoid muscles Rev. CEFAC. 2017;19(6):792-800.

21. Partal I, Aksu M. Changes in lips cheeks and tongue pressures after upper incisor protusion in Class II division 2 malocclusion: a prospective study. Progress in orthodontics. 2017;18(29):2-8.

22. Aktosun T, Machuca A, Sacks P. Determining the shapof a human vocal tract from pressure measurements at the lips. Inverse Problems. 2017;33(11):1-47.

23. Takahashi M, Koide K, Suzuki H, Satoh Y, Iwasaki S. Evaluation of reliability of perioral muscle pressure measurements using a newly developed device with a lip piece. Acta Bioeng Biomech. 2016;18(1):1-9.

24. Jeong D-M, Shin Y-J, Lee N-R, Choung H-W, Pang K-M, Bong J-K et al. Maximal strenght and endurance scores of the tongue, lip, and cheek in healthy, normal koreans. J koreanassoc oral maxilofacsurg. 2017;43(4):221-8.

25. Starmer H, Lyford-Pike S, Ishii LE, Byrne PA, Bohaene KD. Quantifying labial strenght and function in facial paralysis: Effect of targeted lip injection augmentation. JAMA facial plastsurg. 2015;17(4):274-8.

26. Ferreira LM, Pereira HSG, Sena PPM. Estudo cefalométrico das características tegumentares de pacientes com má oclusão de Classe III. Rev. odontol. UNESP. 2014;43(2):98-104.

27. Melo DG, Bianchini EMG. Relationship between electrical activity of the temporal and masseter muscles, bite force, and morphological facial index. CoDAS. 2016;28(4):409-16.

28. Takeuchi G, Kobayashi T, Hasebe D, Funayama A, Mikami T, Saito C. Changes in maximum lip closing force following orthognathic surgery in patients with jaw deformities. J Oral Maxillofac Surg Med Pathol. 2015;27(4):465-9.

29. Rodrigues JA, Silva BNS, Baldrighi SEZM, Paranhos LR, César CPHAR. Interference of mouth breathing with orthodontic treatment duration in Angle Class II, Division 1. Rev. odontol. UNESP. 2017;46(3):184-8.

30. Nakao TH, Bertoz FA, Oliveira DTND, Bertoz APDM, Bigliazzi R. Hábitos bucais como fatores de risco para mordida aberta anterior: uma revisão de literatura. Rev Odontol Arac. 2016;37(2):09-16.
31. Ueki K, Mukozawa A, Okabe K, Miyazaki M, Moroi A, Marukawa $\mathrm{K}$ et al. Changes in the lip closing force of patients with Class III malocclusion before and after orthognathic surgery. Int. J. Oral Maxillofac. Surg. 2012;41(7):835-8.

32. Jung $\mathrm{MH}$, Yang WS, Nahm DS. Maximum closing force of mentolabial muscles and type of malocclusion. Angle Orthod. 2010;80(1):72-9.

33. Caty G, Salazar GS, Butoescu V, Nonclercq O, Tombal B. Evaluation du bénéfice d'un programme supervisé d'exercices chez des patients recevant une thérapie de déprivation androgénique pour un cancer prostatique. Rev Med Liege. 2019;74(1):36-40.

34. Menezes LDF, Neto AMDR, Paulino CEB, StudartPereira LM, Laureano Filho JR. Tongue pressure and endurance in patients with Class II and Class III malocclusion. Rev. CEFAC. 2018;20(2):166-74.

35. Thüer $U$, Ingervall $B$. Pressure from the lips on the teeth and malocclusion. Am J Orthod Dentofacial Orthop. 1986;90(3):234-42.

36. Oliveira BS, Delgado SE, Brescovici SM. Changes of mastication and swallowing in the process of feeding institutionalized elderly. Rev. Bras. Geriatr. Gerontol. 2014;17(3)575-87.

37. Szentesi P, Csernoch L, Dux L, Keller-Pintér A. Changes in Redox Signaling in the skeletal muscle with aging. Oxid Med Cell Longev. 2019; 2019:4617801.

38. Larsson L, Degens H, Li M, Salviati L, Lee YII, Thompson $\mathrm{W}$ et al. Sarcopenia: aging-related loss of muscle mass and function. Physiol Rev. 2019;99(1):427-511.

39. Naini FB, Donaldson AN, McDonald F, Cobourne MT. Assesing the influence of lower facial profile convexity on perceived attractiveness in the orthognathic patient, clinican, and layperson. Oral Surg oral Med Oral Pathol Oral Radiol. 2012;114(3):303-11. 